\title{
Introduction: Marketing Asian-Australianness
}

\section{Olivia Khoo}

The papers collected here originated as part of a panel discussion at the Asian Australian Identities 2 conference, 'Marketing Asian-Australianness', which I organised and chaired. ${ }^{l}$ The invited speakers were given very loose parameters within which to discuss the topic 'Marketing Asian-Australianness' in literature.

Compared to the field of Asian American literature, Asian-Australian literature is still very new. As a literary category, Asian-Australian writing is slowly beginning to establish itself although it remains far less institutionalised (both in publishing and in academia) than its U.S. counterpart. In many ways, the category 'Asian-Australian literature' is still in the process of being defined. It both straddles, and seeks to differentiate itself from, the sometimes conflicting constellations of diasporic Asian literature and Australian literature. Nevertheless, there is a strong and ever-growing body of works and writings that we might call 'Asian-Australian literature' (literature by or about Asian-Australians) in its own right.

For a body of work as fledgling as this, marketing remains an important and ever-present consideration for both authors and publishers. Asian American literature has already fought (though not necessarily won) many of its battles over age-old questions including the right or the necessity of ethnic authors to write about their identity; that is, their cultural or ethnic identity. Rey Chow calls this compulsion towards ethnic or group identity a form of 'coerced mimeticism' (18). No matter how 'nonmimetic, experimental, subversive, or avant-garde' such writing may in fact be, it is nonetheless marketed, classified and received in the West as corresponding to a preconceived entity known as 'China', 'Singapore', or 'the Philippines', etc. (22). There is always another home, another origin.

In the early 1990s, a heated debate in Asian American literary studies involved Maxine Hong Kingston's acclaimed The Woman Warrior: Memoirs of a Girlhood Among Ghosts, wherein critics such as Frank Chin decried Hong Kingston's use of fictional (mythic) elements and her distortion of Chinese legends in a novel that was represented as an 'autobiography'. These critics argued that the label was simply a marketing ploy, despite Hong Kingston's assertions that she had

\footnotetext{
${ }^{1}$ The Asian Australian Identities 2 conference was held in Melbourne, 28-30 June 2007, and was organised by the Asian Australian Studies Research Network.
} 
no input into its classification. Over a decade later, similar anxieties continue to haunt Asian-Australian authors.

In his paper "No One Puts Baby in a Corner": Inserting Myself into the Text', Tom Cho notes the persistence of certain issues plaguing the emergent field of Asian-Australian literature, including the autobiographical 'requirement'. However, rather than attempt to avoid this impulse altogether, Cho finds alternative ways of writing himself, literally, into his work, here, through the lens of popular culture. Cho's strategies of 'inserting himself into the text' add layers of complexity to the problem of how to represent one's identity without necessarily reducing it to the form of an autobiography.

Simone Lazaroo's 'Not Just Another Migrant Story' similarly attends to the relationship between autobiography and marketing. Lazaroo notes that books by Asian-Australian authors tend to be marketed as being purely (or predominantly) about migration and identity and are therefore regarded as being limited in their appeal or approach. By 'fixing' an ethnic or cultural location, for example through 'back cover blurbs' and book reviews, novels by Asian-Australian writers are made more easily understandable, and thus consumable, but correspondingly become viewed as being too narrow or specialised to merit wider interest. In her paper Lazaroo very generously attends to the many questions I posed to the panel, sharing her experiences as a successful writer and providing an insight into ways of negotiating the field.

Merlinda Bobis' paper, 'Voice-Niche-Brand', also offers a deeply personal yet carefully crafted critical model through which to negotiate the market. Bobis outlines a three-staged framework, which involves finding a voice, developing a niche, and then moving beyond the niche to develop a brand. Bobis' own 'niche' involves her performing her work, thereby creating an embodied experience for the audience. In order to 'brand' herself, however, Bobis has had to assume different tactics in packaging and 'selling' herself to an international audience. She raises the question of whether we can in fact consider Asian-Australian to be a brand, and if so, what does it mean to the market at this time?

From these different perspectives and positionings, it becomes clear that there is no one way to 'write' Asian-Australianness, meaning there can be no one way to market it. We can only hope that the market itself catches up to this fact. The insights provided by these writers are relevant not only to those working in the field of literature but for any cultural practitioner confronted by questions of value, artistic freedom, and the commodification of their ethnicity and identity. 
Olivia Khoo is a Targeted Research Fellow in the School of Media, Culture and Creative Arts at Curtin University of Technology. She is the author of The Chinese Exotic: Modern Diasporic Femininity (Hong Kong University Press, 2007).

\section{Works Cited}

Chin, Frank, Jeffrey Paul Chan, Lawson Fusao Inada and Shawn Wong, eds. The Big Aiiieeeee!: An Anthology of Chinese American and Japanese American Literature. New York: Plume, 1991.

Chow, Rey. 'Introduction: On Chineseness as a Theoretical Problem.' boundary 2, 25.3 (1998): 1-24. 